\title{
Identifying Cognitive Obstacle on the Topic of Definite Integral among Prospective Teacher
}

\author{
Kartinah, Faculty of Mathematics and Natural Science, Universitas Negeri Malang, Indonesia \\ Toto Nusantara, Faculty of Mathematics and Natural Science, Universitas Negeri Malang, Indonesia \\ Sudirman, Faculty of Mathematics and Natural Science, Universitas Negeri Malang, Indonesia \\ Tjang Daniel, Faculty of Mathematics and Natural Science, Universitas Negeri Malang, Indonesia
}

\begin{abstract}
In the calculus subject, there is definite integral material, and on that material, students often encounter obstacles. Obstacles are all things that hinder students from learning. Cognitive obstacles are one of four known types of obstacles, three of which are: epistemological obstacles, didactive obstacles, and ontogenic obstacles. Cognitive obstacles are the knowledge a person has and are usually sufficient to solve a particular problem, but this knowledge is inadequate when the person is confronted with a new problem. This study was conducted at the Mathematics Education Study Program, a university in the city of Semarang by taking two subjects. Both of these subjects experience cognitive obstacles when completing definite integral tasks.
\end{abstract}

Keywords: Cognitive Obstacles, Definite Integrals, Definite Integral Task, Prospective Teacher, Qualitative Research.

$\begin{array}{lll}\text { Received: 07.12.2020 } & \text { Accepted: 13.01.2021 } & \text { Published: 05.02.2021 }\end{array}$

\section{INTRODUCTION}

Mathematics students in the early semester were familiar with the concept of Definite Integral. Starting with an understanding of Riemann Sums where defining definite integrals is composed of a concept of limits on Riemann Sums of a function. Basically, Riemann Amount is a numerical approximation (approach) to find the area under the curve of a function by dividing the interval into $\mathrm{n}$ sub-strings.

In learning on integral, students often have difficulty in determining what methods to use to solve these integrals, because there are many methods of solving integral problems. However, when students are faced with definite integral problems, in addition to determining the method to be used, they are also faced with problems regarding the upper limit, the lower limit, and the value that lies between the upper limit and the lower limit.

Various studies have been carried out to investigate the difficulties of students in Calculus subject. Some of the difficulties identified include poor understanding of basic concepts, an inability to formulate mathematical problems, and a lack of mastery in algebraic, geometric and trigonometric skills (Yudariah \& Roselainy, 2001). Determining the difficulty of learning mathematics in their research, Tall \& Razali (1993) has shown that students have difficulties in using concepts and coordinating operations. While they also stated that students perceiving operational experience more problems than students who perceive conceptually.

In his theory of cognitive development, Piaget argues that each individual adapt. Adaptation is defined as the process of adjusting the scheme in responding to the environment by means of assimilation and accommodation (Sukoriyanto et al., 2016). When a person discovers a new condition that is in accordance with the scheme he has, he will adapt in the form of assimilation, whereas when the scheme he has does not match the new condition, he will adapt in the form of accommodation (Netti et al., 2016). Furthermore, Piaget in Sukoriyanto et al. (2016) said that the process of adaptation to individual accommodation is caused by a disequilibrium condition, that is, an imbalance between what is known and what is encountered. The condition of students' difficulties in assimilating new knowledge into cognitive schemes in the accommodation process is shown as cognitive conflict.

\section{Cognitive Obstacles}

The term cognitive obstacle was introduced more widely by some researchers (Bachelard, 1938; Herscovics, 1989; Tall, 1989; Cornu, 1991). According to Bachelard (1938), cognitive obstacles are part of the students' knowledge that are generally satisfactory when solving certain problems and penetrate the mind, but then when faced with new problems that knowledge proves to be inadequate and difficult to adapt. Tall (1989) chose to interpret the notion of cognitive obstacles in Piaget's theory, where students 
are confronted with new ideas that cannot be attached to existing cognitions, unable to cope adequately with new information. According to Cornu (1991) cognitive obstacles are the product of previous student experiences and the internal processes of their experiences and are manifested when students experience difficulties in the learning process. In this study, what is meant by cognitive obstacles is a situation where prior knowledge and internal knowledge processes are appropriate in completing certain tasks but are unable or difficult to adapt in completing other tasks.

The term cognitive obstacles lies in the process of assimilation and accommodation (Herscovics, 1989). Assimilation is the integration of things that must be known into some existing cognitive structures, while accommodation is a change in the cognitive structure of students required by the acquisition of new knowledge (Herscovics, 1989). Subanji and Supratman (2015) have successfully described the process of assimilation and accommodation through a chart in their article. According to Subanji and Nusantara (2016), the assimilation process occurs when there is a match between the new stimulus with the schemata that are already in the minds of students, while the accommodation process occurs when the schemes owned by students do not match the stimulus, so it is necessary to change the old scheme or form a new scheme so the scheme is formed according to the stimulus. The term cognitive obstacles by some authors used other terms, including: misunderstanding (Ormond, 2012), difficulties in understanding (Sahin et al., 2015), incorrect understanding (Schoenfeld, 1994), and lack of understanding, cognitive obstacle, conflict cognitive (Tall, 1977).

In this case, cognitive obstacles will hinder the process of assimilation and accommodation so that students experience obstacles in acquiring knowledge. Tague and Baker (2014) state that the transition process of students' mathematical thinking also experiences cognitive obstacles. Cognitive obstacles raised by Tague and Baker (2014) are the lack of prerequisite knowledge that students must master in taking material. Eraslan (2005) found cognitive obstacles faced by students in learning mathematics, including the lack of making mathematical connections and investigations and other cognitive obstacles arising from the need to make foreign ideas become better known.

\section{METHOD}

This study is a descriptive exploratory study and uses a qualitative research design to explore cognitive obstacles related to Definite Integral. The instruments used in this study were written tests and interviews. The written test used is an Integral subject to explore cognitive obstacles and interview instruments. The two chosen subjects are students who have taken the Integral Calculus course then given Definite Integral Tasks. Definite Integral Tasks a number of one problem which before being used for research, has been validated by two experts so as to obtain input, whether it is feasible or not. The interview instrument in this study uses structured interviews. Based on the correctness of the answers, students are grouped into two namely students with correct answers and students with incorrect answers. Then the students' answers were selected which showed the most cognitive obstacles from each group as the subjects of this study. MF was chosen as the subject with the correct answer and RH as the subject with the wrong answer.

Indicators of cognitive obstacles in this study are if the ability of previous students, who have been well mastered are unable or difficult to adapt to complete the given task. To investigate the cognitive obstacles of students, we designed the Definite Integral Task adapted from Purcell (1997) as follows:

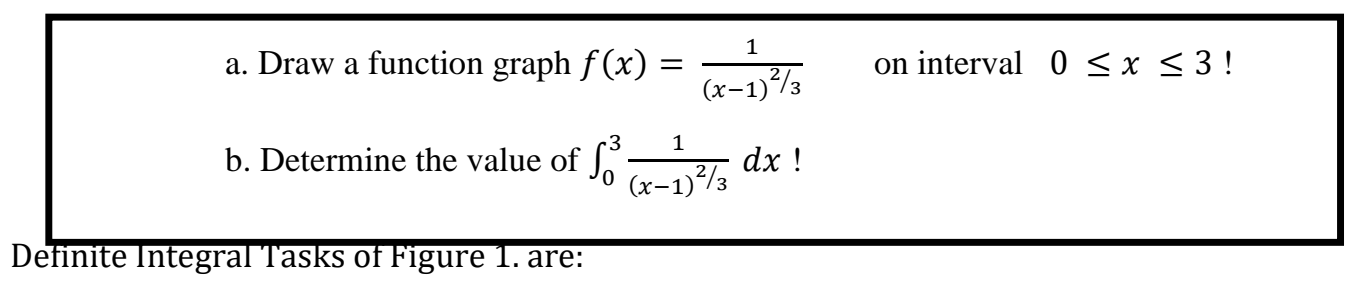

Figure 1. Definite Integral Tasks 


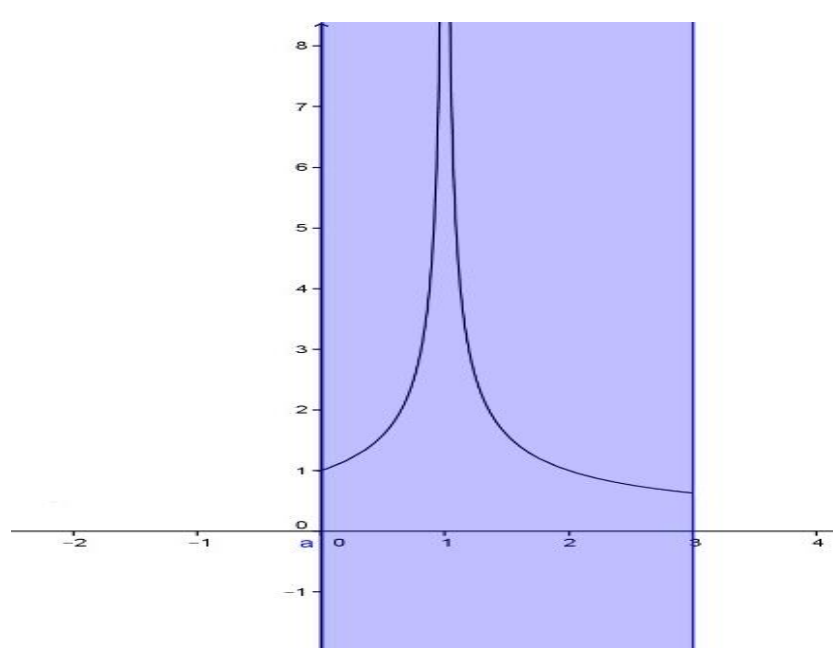

Figure 2. Graph of functions

a) $f(x)=\frac{1}{(x-1)^{2 / 3}}$

b) $\int_{0}^{3} \frac{1}{(x-1)^{2 / 3}} d x=\int_{0}^{1} \frac{1}{(x-1)^{2 / 3}} d x+\int_{1}^{3} \frac{1}{(x-1)^{2 / 3}} d x$

$$
\begin{aligned}
& =\lim _{t \rightarrow 1^{-}} \int_{0}^{t} \frac{1}{(x-1)^{2 / 3}} d x+\lim _{t \rightarrow 1^{+}} \int_{t}^{3} \frac{1}{(x-1)^{2 / 3}} d x \\
& =\lim _{t \rightarrow 1^{-}}\left[3(x-1)^{1 / 3}\right]_{0}^{t}+\lim _{t \rightarrow 1^{+}}\left[3(x-1)^{1 / 3}\right]_{t}^{3} \\
& =3 \lim _{t \rightarrow 1^{-}}\left[(t-1)^{1 / 3}+1\right]+3 \lim _{t \rightarrow 1^{+}}\left[2^{1 / 3}-(t-1)^{1 / 3}\right] \\
& =3+3\left(2^{1 / 3}\right) \approx 6.78
\end{aligned}
$$

The problem was chosen because this type of non-routine question can be used to reveal the existence of a cognitive obstacle student process. Data analysis techniques in this study used descriptive qualitative analysis techniques. Analysis of the data used is to describe the process of internal cognitive obstacles that occur when students solve mathematical problems. Based on student answers and interview results, cognitive signs and obstacle that occur internally in the cognitive structure of each subject are described when Definite Integral Tasks.

\section{RESULTS AND DISCUSSION}

We present data by analyzing the subject's answers and also the discussion in this section. Based on the written answers of the subjects of 32 students at the University of PGRI Semarang in completing the Integral Tasks of course presented in the following table:

Table 1. Results of student answers

\begin{tabular}{|l|l|l|l|}
\hline $\begin{array}{l}\text { Answer } \\
\text { Category }\end{array}$ & $\begin{array}{l}\text { Number of } \\
\text { Students }\end{array}$ & $\begin{array}{l}\text { Number of Experiencing } \\
\text { Cognitive Obstacles }\end{array}$ & $\begin{array}{l}\text { Amount Does Not Experience } \\
\text { Cognitive Obstacles }\end{array}$ \\
\hline Correct & 8 & 4 & 4 \\
\hline False & 24 & 4 & 20 \\
\hline
\end{tabular}

\section{Signs of Subjects Cognitive Obstacles}

The signs of MF and RH subjects experiencing cognitive obstacles were identified from the answer sheets as well as the researchers' observations of the subject's behavior when completing the Definite Integral Task. MF is a subject that answers incorrectly for part a problems (drawing a function graph) but answers correctly for part b problems (looking for integral values of course). Conversely, RH subjects are subjects who answer correctly for part a problems (draw a graph of functions) but answer incorrectly for part b problems (look for integral values of course). MF and RH experience cognitive obstacles marked by the abilities that are already possessed by the subject, which have been well mastered unable or difficult to adapt to complete the given task. 


\section{Written Test Results and MF Subject Interviews}

Following are the results of MF's written work.

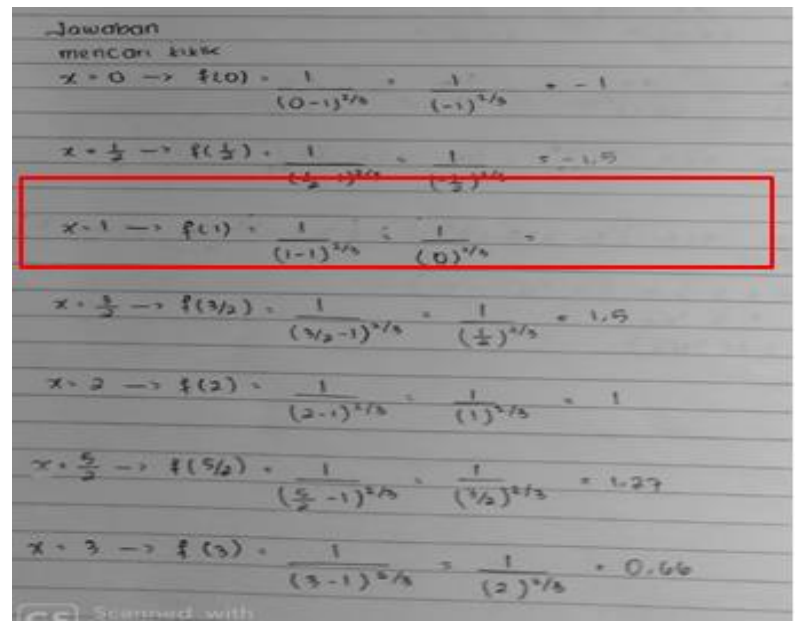

Figure 3. Written work subject of $M F$

Figure 3 shows the chronology of MF thinking when completing drawing graph functions $f(x)=\frac{1}{(x-1)^{2 / 3}}$ requested in the problem. In drawing graphics, the initial step of MF is to find the coordinates of the coordinates by substituting the value of $\mathrm{x}$ that is within the requested interval that is interval $0 \leq x \leq 3$. The work done by MF was successfully carried out when taking the point $\mathrm{x}=0$ and $\mathrm{x}$ $=1 / 2$, but for $\mathrm{x}=1$, MF subjects leave the value blank. While for the values $\mathrm{x}=3 / 2,2,5 / 2$ and $3 \mathrm{MF}$ can find the value of $y$.

The following are excerpts of interviews with MF subjects

$\mathrm{P}-2 \quad$ : Is this the answer 1a? 1a requested to draw a graph

MF-2 :Yes ma'am.

$\mathrm{P}-3 \quad$ : This appears like this how is the explanation?

MF-3 : Yes ma'am, I'm confused, if the denominator is zero, the result is undefined or not up to date? So I emptied ma'am.

Based on the confirmation of the MF subject for written answers, it was revealed that the subjects were skeptical about result $\frac{1}{0}$. Furthermore, from the pictures made by the subjects, there is an inconsistency between the coordinates of the points $(\mathrm{x}, \mathrm{y})$ obtained by the subject and the graphs made.

Following are the results of MF's written work.

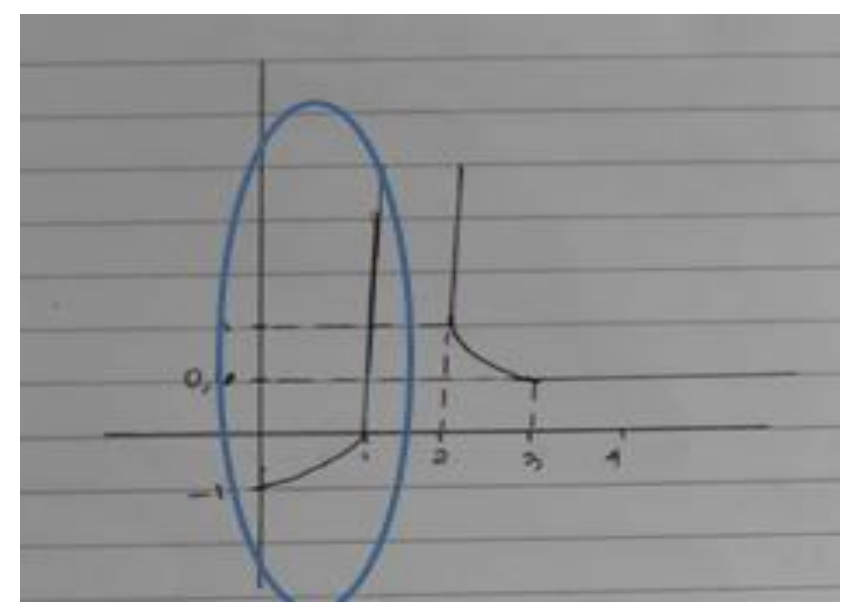

Figure 4. Written work of MF subjects

In Figure 4 above, it appears MF subjects are wrong in drawing graphics $f(x)=\frac{1}{(x-1)^{2 / 3}}$ although in the initial stages of working on the MF do the right thing, namely in determining the coordinates. For the abscissa point equal to one $(x=1)$, MF states "confused" about what the value of $y$ is, 
but MF subjects draw it with a vertical straight line. When this was asked, MF again answered "confused". The MF subject experiences cognitive obstacles where the knowledge that the subject already possesses turns out to be faced with new problems (Drawing graphs of functions $f(x)=\frac{1}{(x-1)^{2 / 3}}$ ), Such knowledge is inadequate to solve the problem.

The results of the written work on question $1 \mathrm{~b}$ are determines the integral results of course $\int_{0}^{3} \frac{1}{(x-1)^{2 / 3}} d x$

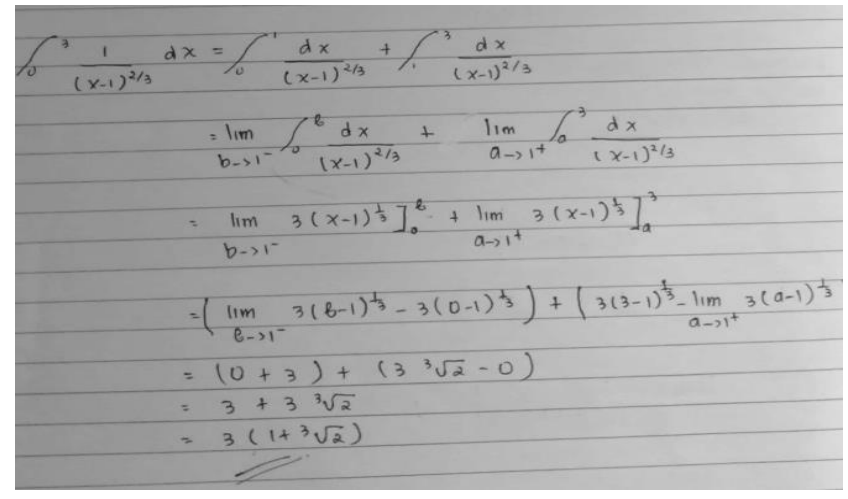

Figure 5. Written work subjects of $M F$

Figure 5 shows that MF correctly answered this part b problem and does not appear to have cognitive obstacles. The excerpts of interviews with MF showed different things.

P-20 : Is it necessary to read the problem over and over again to understand?

MF-20 : if the question about part a is not Ma'am, I immediately understand it but the question of part $b$ is I read it over and over again.

P-21 :If for part B, how can it be solved?

MF-21 : I am ambiguous ma'am, confused about integrating it.

P-22 : What makes the boundaries or functions confused?

MF-22 : The function is ma'am.

P-23 : Why the function?

MF-23 : Oh, the limit, ma'am, makes you confused.

P-24 : Why?

MF-24 : Because I see the function graph $f(x)$ at $x=1$, I don't know how many $y$ 's. It Is Undefined or Not Up To.

PS-25 : After working on this problem, is there any relation between the graphic image and finding the integral?

MF-25 : The number might be Ma'am. The coordinates are uncertain, ma'am. If $x=3$ is not Zero Ma'am.

\section{Written Test Results and RH Subject Interviews}

In drawing the function graph, according to the request in the problem, RH has done the right step, only made a few mistakes in drawing the curve. The requested interval is from Nola to Three, while $\mathrm{RH}$ subjects make the curve exceed the requested interval. The following results are written RH work.

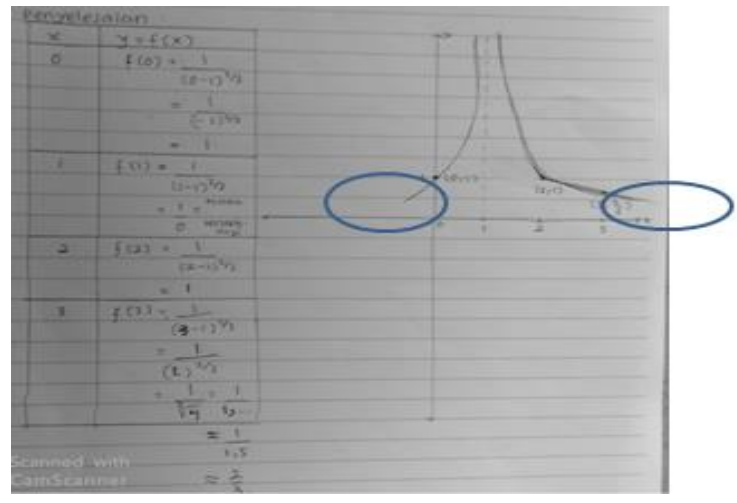

Figure 6. The written work of RH subjects 
For part b, RH completes the integral course by using the standard integral formula that has been known since high school, namely $\int x^{n} d x=\frac{1}{n+1} x^{n+1}+c$

In addition, RH also uses the basic theorem of calculus, namely: Let $\mathrm{f}$ be continuous (hence integrated) in [a, b] and suppose $\mathrm{F}$ is any anti-derivative in [a, b]. Then: $\int_{a}^{b} f(x) d x=F(b)-F(a)$

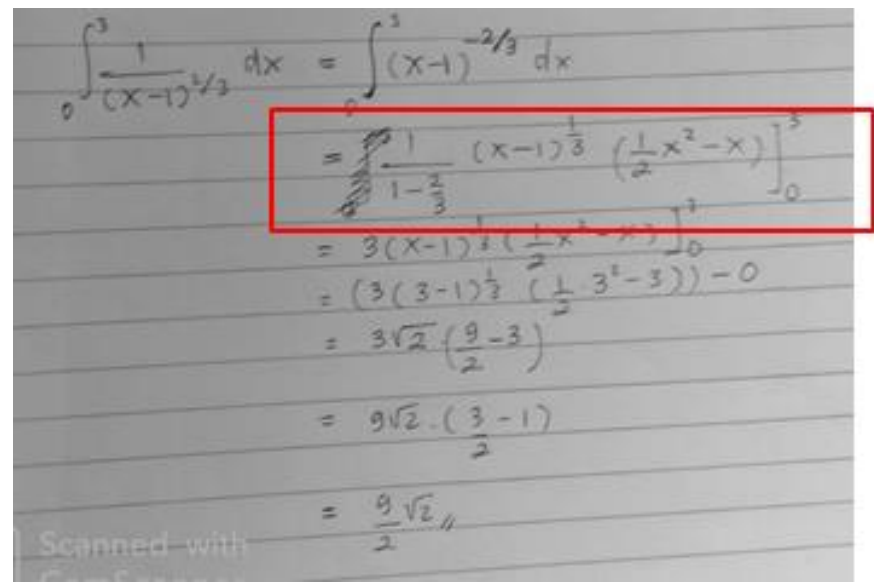

Figure 7. RH subject written work

After synchronizing with the results of the interview, it can be seen here that RH did not find any connection between the graph and the questions in part $b$. The following is an interview with RH:

P-31 : When it comes to part number $b$, when you first read the question, what comes to mind?

RH-31 : Mmmmmh like working on an ordinary integral.

P-32 : OK, how do you do it? This uses the integral formula of course huh?

$\mathrm{RH}-32$ : Yes.

P-33 : The formula is $\int x^{n} d x=\frac{1}{n+1} x^{n+1}$ huh?

RH -33: : Iya Bu

P-34 : Continue, minus no?

RH-34 : Yes ma'am after that reduced the upper limit to the lower limit.

P-35 : Didn't cross using another method?

RH-35 : Maybe there are ma'am, but I don't master the Trigonometry formula

P-36 : ooo was taken to Trigonometry? Do you think this is the Integral that produces the Inverse Trigonometry function?

RH-36 : Yes ma'am, but I did not do it that way.

RH subjects experienced cognitive obstacles where the knowledge that the subject already possessed turned out to be when faced with a new problem (Looking for a function value graph of $\int_{0}^{3} \frac{1}{(x-1)^{2 / 3}} d x$ ),

Such knowledge is inadequate to solve the problem.

Of the two subjects MF and RH who experience cognitive obstacles, this is in line with the study of Tall (1993) which states various studies have been conducted to determine the difficulty in analyzing; and some of the difficulties are important concepts learned inadequately by students, the inability to formulate mathematical problems, and the lack of students' algebraic, geometric, and trigonometric abilities. In examining the difficulties faced by students in the concept of multiple algebra, Yudariah \& Roselainy (2001) obtained four categories of student difficulties, namely: zone and space review (inspection of zones and spaces), graphical interpretation (interpreting the graphics), algorithmic errors (algorithmically mistakes), and algebraic operation mistakes. For MF subjects making mistakes in drawing graphics, but correct in working on the problem of looking for integrals of course. Conversely, RH subjects are correct in drawing graphics, but make mistakes in finding integrals, of course. Cognitive obstacles experienced by the two subjects are similar that is not able to find the relationship between the graph with the requested integration problem.

\section{CONCLUSIONS AND SUGGESTIONS}

The conclusion of this research is students who fail to find the relationship between graphic images by means of an integral solution that causes it to lead to incorrect problem solving. While students who are able to build relationships between graphic images by means of integral resolution, to bring it to the 
correct problem solving. Based on these findings, it is recommended that lecturers emphasize students on the relationship between the function graph with the function integral.

\section{REFERENCES}

Bachelard G. 1938: (reprinted 1983) La Formation de l'esprit Scientifique, J. Vrin., Paris,France

Cornu. 1991. Apprentissage de la notion de limite: conceptions et obstacles, Thèse de 3me Cycle, Grenoble.

E. J. Purcell 1997. Kalkulus dan Geometri Analitik jilid 1. I Nyoman Susila et al (Trans.). Jakarta. Erlangga

Eraslan, Ali. 2005. A Qualitative Study: Algebra Honor Students' Cognitive Obstacles as They Explore Concepts of Quadratic Functions. Florida State University Libraries Foshay, Rob. 2003. Principle for Teaching Problem Solving. Plato Learning Inc.

Herscovics, N.1989. Cognitive obstacles encountered in the learning of Algebra. In: C. Kieran, \& S. Wagner (Eds.), Research issues in the learning and teaching of algebra, pp. 60-86. Hillsdale, NJ: Lawrence Erlbaum Associates.

J. Sukoriyanto, N. Toto, S. Subanji, and D. C. Tjang, 2016. "Students thinking process in solving combination problems considered from assimilation and accommodation framework," Educational Research and Reviews, vol. 11, no. 16, pp. 1494-1499.

Ormond, C. 2012. Developing "algebraic thinking": two key ways to establish some early algebraic ideas in primary classroom, Australian Primary Mathematics Classroom, 17(4), 13-21.

S. Netti, T. Nusantara, S. Subanji, A. Abadyo, and L. Anwar. 2016. "The Failure to Construct Proof Based on Assimilation and Accommodation Framework from Piaget," International Education Studies, vol. 9, no. 12, p. 12.

Sahin, Z., Yemez, A.A. \& Erbas, A.K. 2015. Relational understanding of the derivative concept through mathematical modeling: A case study, Eurasia Journal of Mathematics, Science \& Technology Education, 11(1), 177-188

Schoenfeld, A.H. 1994. Reflections on doing and teaching mathematics. In A.H. Schoenfeld (Ed.): Mathematical thinking and problem solving (53-70). Hillsdale, NJ: Erlbaum

Subanji, \& Nusantara, T. 2016. Thinking Process of Pseudo Construction in Mathematics Concepts. International Education Studies; Vol. 9, No. 2.

Subanji, \& Supratman. 2015. The Pseudo-Covariational Reasoning Thought Processes in Constructing Graph Function of Reversible Event Dynamics Based on Assimilation and Accommodation $\begin{array}{lllll}\text { Frameworks. J. Korean } \quad \text { Soc. Math. Educ., 19(1), } & \text { 55-73. }\end{array}$ http://dx.doi.org/10.7468/jksmed.2015.19.1.000

Tague, J., Baker, G. R. 2014. Flipping the Classroom to Address Cognitive Obstacles. 12th ASEE Meeting Conference and Exposition. American Society for Engineering Education, Indianapolis.

Tall, D. 1977. Cognitive conflict and learning of mathematics. Retrieved 22.09.2010, from http://www.warwick.ac.uk/staff/David.Tall/pdfs/dot1977a-cog-confl-pme.pdf.

Tall, D. 1989. New Cognitive Obstacles in a Technological Paradigm. Research Issues in the Learning and Teaching of Algebra, N.C.T.M., 87-92.

Tall, D. O., 1993. Students Difficulties in Calculus. Proceeding of Working Group 3 on Students' Difficulties in Calculus. Proceedings of the 7th International Congress on Mathematical Education (ICME), Quebec, Canada, 3:13-28

Tall, D.\& Razali, M.R., 1993, Diagnosing Students' Difficulties In Learning Mathematics. Int. Jnl of Math. Edn in Sc. \& Tech., Vol 24, No. 2, 209-222.

Yudariah, M.Y. \& Roselainy, A.R., 2001, Students' Difficulties with Multiple Integration: A Preliminary Study, 3rd Southern Hemisphere Symposium, South Africa. 